\title{
Concept of Integrity, Reliability and Safety of Energy and Transport Systems for Cold Climate Regions
}

\author{
Valeriy V. Lepov ${ }^{1, *}$, Nikolay A. Petrov², Dmitry V. Prokhorov ${ }^{2}$, Nikita V. Pavlov², and Vasiliy E. Zakharov ${ }^{2}$ \\ ${ }^{1}$ Larionov Institute of Physical and Technical Problems of the North SB RAS, Fracture Modelling Department, 677980 Yakutsk, Russia \\ ${ }^{2}$ Larionov Institute of Physical and Technical Problems of the North SB RAS, Energy Problems Department, 677980 Yakutsk, Russia
}

\begin{abstract}
The concepts of providing the integrity, reliability and safety of the energy and transport systems in the Arctic zone are considered. The inadmissibility of using the concept of acceptable, or tolerable, risk to ensure the operational safety of potentially hazardous facilities used in extreme environment has been validated by the history and reasons of risk analysis reviewing. The new concept for transport and energy systems operating in cold climates has been proposed to include in the security concept flexible information monitoring and control systems that take into account the state of environment, the engineering system and the operator himself. The promptness of implementation of the new concept of renewable development is dictated by the modern transitional state of society from thoughtless consumption of resources to the minimization of environmental damage and the inadmissibility of human casualties, called Industry 5.0.
\end{abstract}

\section{Introduction}

The concept of safety in modern regulatory documents is used as a synonym for providing some acceptable, or permissible, risk, which has a quantitative value, which is taken to ensure the operability of a structure or machine.

But in reality, safety is the opposite of hazard, and full-time operation eliminates any risk. Compliance with safety standards is a strict obligation of any production, construction, operation of a potentially hazardous facility. The risk is assessed only for events that can occur, subject to these standards. Risk analysis is intended rather to search a priori for unaccounted for hazards, or "weaknesses", in order to develop additional safety measures.

Therefore, setting an acceptable risk as a safety criterion only allows one to get away from the general problem of compliance with technical standards, from the human factor, the solution of social and psychological problems - and reduce it to a purely technical, engineering problem. The introduction of risk acceptability criteria into legislative practice leads to an increase in technogenic hazards for the majority of citizens, since it selfishly justifies non-compliance with safety requirements.

For example, at most modern industrial enterprises and concerns, including the domestic oil and gas complex, equipment reliability and integrity management (ESCO) is implemented on the basis of a risk-based approach and the concept of acceptable risk, in order to minimize economic damage and increase the overall economic result [1].
Moreover, in November 2017, a new version of the ISO / IEC 17025: 2017 standard was released, and in 2019 - the edition of GOST ISO / IEC 17025, where the emphasis on the organizational activities of the testing laboratory (TL) for quality assurance, including the use of process approach and risk management, which can be attributed to the main tools of the quality management system (QMS) IL [2]. The emphasis is on the conditions for meeting the requirements for risk management. Risk management moves into research laboratories, using tools: "brainstorming" and "consequences and probability matrices", which, generally speaking, are not applicable to security issues.

The need for a new concept of security is dictated by the new informational "knowledge society" and the fourth industrial revolution, so-called. "Industry 4.0" [3], as well as by the latest developments and changes in global economics associated with the pandemic, and forced to rethink modern technologies of the consumer society, the concept of "acceptable risk" and the fiftyyear of sustainable development history.

\section{History of the issue}

Ensuring the safety of the population and the environment is a very complex engineering problem, the solution of which is impossible without improving and deepening engineering training in the field of reliability research, forecasting and ensuring the safety of engineering systems. In a number of industrialized countries, the study of the safety of engineering systems as a separate independent activity was introduced into practice in the sixties (for example, we can cite the activities of the United States since the 50s to create a

\footnotetext{
*Corresponding author: lepov@iptpn.ysn.ru
} 
security system for aerospace technology). The focus has shifted from analysing the behaviour of individual elements of various types (electrical, mechanical, hydraulic) to the causes and consequences caused by the failure of these elements in the corresponding system. Failure Tree, Consequence Tree, Sequential Examination Method, Expert Judgment and other failure detection methods have been adopted by specialists working in the chemical and other hazardous industries, just from the military and aerospace research. It was in these countries that the 60 s were marked by the beginning of the wide publication of scientific works related to the described field of research in Russia. Moreover, such the works had single editions. This followed from the concept of "absolute safety" of domestic technologies and equipment. Until recently, this concept was the foundation on which safety standards were built. Affected by the specificity of the political, economic and social development of the former USSR, which led to a lag of at least 20 years [4-5], in research in the field of industrial safety, life safety, and ecology, this attitude to safety problems hindered the formation of specialists' ideas about the principles and methods of ensuring industrial and environmental safety, which produced a lag in all areas of engineering and educational activities: design, manufacturing, operation, safety supervision, training of specialists, and on the growth of the number and scale of extreme situations and accidents at industrial enterprises, transport systems, etc. The requirement of "absolute safety", i.e. "zero risk" ultimately led to costly and even tragic consequences for the population and economy of the country. Specialists operating engineering systems and servicing hazardous technologies in the chemical industry, energy systems and pipeline transport were methodologically unprepared for the search and analysis of critical failures leading to accidents. The level of knowledge in matters of life safety in the technosphere lagged behind the level of complexity and development rates of technology, technology, engineering systems [6].

\section{Risk analysis concepts}

Currently, the following concepts of risk analysis have been adopted [6]:

- the technocratic risk concept based on the analysis of the relative frequencies of emergencies (emergencyinitiating events) as a way of setting their probabilities. When used, the available statistics are averaged over scale, population groups and time;

- an economic risk concept in which risk analysis is considered as part of a more general cost-benefit study. In the latter, risks are expected losses of utility arising from certain events or actions. The ultimate goal is to allocate resources in such a way as to maximize their usefulness to society;

- the psychological risk concept is centered around research on interindividual preferences for probabilities in order to explain why individuals do not form their opinion about risk on the basis of mean values; why people react according to their perception of risk rather than an objective level of risk or scientific risk assessment;

- the social (culturological) risk concept is based on a social interpretation of undesirable consequences, taking into account group values and interests. Sociological risk analysis links society's judgments about risk to personal or public interests and values. The social approach assumes that existing cultural prototypes determine the way of thinking of individuals and public organizations, forcing them to accept some values and reject others.

The technocratic concept that is applicable to the engineering systems that we are considering. Within the framework of the technocratic concept, after identifying the risks (identifying the fundamentally possible risks), it is necessary to assess the consequences to which they can lead, i.e. the likelihood of related events and the associated potential damage. For this, risk assessment methods are used, which are generally divided [7] into phenomenological, deterministic and probabilistic. Let's consider the areas of their application.

The phenomenological method is based on determining the possibility of emergency processes proceeding from the results of the analysis of the necessary and sufficient conditions associated with the implementation of certain laws of nature. This method is the easiest to use, but it gives reliable results if the operating states and processes are such that it is possible to determine the state of the components of the system under consideration with a sufficient margin, and is unreliable near the boundaries of an abrupt change in the state of substances and systems. The method is preferable when comparing safety margins of various types of potentially hazardous objects, but it is of little use for analysing branched emergency processes, the development of which depends on the reliability of certain parts of the object and/or its protective equipment [8].

The deterministic method provides for the analysis of the sequence of stages in the development of accidents, starting from the initial event through the sequence of the expected stages of failures, deformations and destruction of components to the steady-state final state of the system. The course of the emergency process is studied and predicted using mathematical modeling, building simulation models and performing complex calculations. The deterministic approach provides clarity and psychological acceptability, as it makes it possible to identify the main factors that determine the course of the process. In nuclear power, this approach has long been the main one in determining the degree of safety of reactors. The disadvantages of this method are the potential to lose sight of some rarely realized but important chains of events during the development of an accident; the difficulty of constructing sufficiently adequate mathematical models; complex and expensive experimental studies are required to test the computational programs [6].

The probabilistic method of risk analysis involves both an assessment of the probability of an accident and the calculation of the relative probabilities of one or another path of development of processes. In this case, branched chains of events and equipment failures are analyzed, a 
suitable mathematical apparatus is selected and the total probability of accidents is estimated. The main limitations of probabilistic safety analysis are associated with insufficient information on the distribution functions of parameters, as well as insufficient statistics on equipment failures. In addition, the use of simplified design schemes reduces the reliability of the resulting risk assessments for severe accidents. Nevertheless, the probabilistic method is currently considered one of the most promising for future applications [6].

Based on the probabilistic method, various methods for assessing natural and man-made risks for the population can be built, which, depending on the available (used) initial information, are divided into [6]:

- statistical, when the probabilities are determined from the available statistical data (if any). The construction of such risk models requires a large amount of data obtained from observations or experiments, which is not always feasible;

- theoretical and probabilistic, used to assess the risks from rare events, when statistics are practically absent;

- expert (heuristic), based on the use of subjective probabilities obtained using expert assessment; are used in assessing complex risks from a set of hazards, when not only statistical data are missing, but also mathematical models (or the models are too coarse, i.e., their accuracy is low).

\section{Analysis of failures and disasters in the energy industry and transport}

At present, the adverse effects of energy facilities on people and the environment during their construction and operation have reached such proportions that they force us to consider the problem of safety of energy facilities as extremely important. Examples of major accidents with significant material and social damage that have occurred in recent decades in the power supply systems of a number of settlements in Sakha Republic (Yakutia) indicate that this problem remains particularly relevant [9].

The creation of databases on failures, as well as improving the quality of collection of primary statistical information, is of great importance for the development of a strategy for managing the operation of energy systems and improving the accuracy of analysis. In order to present the causes and consequences of emergency situations, some descriptions of accidents that occurred in Sakha Republic (Yakutia) are considered. For the analysis, examples were selected that contain more complete descriptions of various interrelated causes and consequences of accidents. Some of them are shown in Table 1.

In order to single out the most dangerous element in the power supply system, accidents are distributed among the main system elements, then accidents are distributed among the units of the unit within the system element. It should be noted that accidents occur in all the main elements of the power supply system, but their number and frequency of occurrence are different.

The analysis shows that the tendency to maintain high values of the risk of accidents in power supply systems is mainly due to the following reasons [10]:

1. Influence of climatic conditions on the peculiarities of the operation of engineering systems (low temperature, wind gusts, floods, thawing of frozen soils of the foundations of energy facilities);

2. High wear of engineering systems and equipment;

3. Insufficient level of development of the safety management system during the operation of electrical, water supply and heating networks;

4. Low qualification of service personnel or the socalled "human factor".

Table 1. Examples of accidents in the power supply system of Sakha Republic (Yakutia).

\begin{tabular}{|c|c|c|c|c|c|c|c|}
\hline № & Description & Accident site & $\begin{array}{l}\text { Detection } \\
\text { date and } \\
\text { time }\end{array}$ & $\begin{array}{c}\text { Eliminati } \\
\text { on date } \\
\text { and time }\end{array}$ & Accident causes & Damage & $\begin{array}{c}\text { Number of } \\
\text { affected } \\
\text { population }\end{array}$ \\
\hline 1 & $\begin{array}{l}\text { Disconnection of the } \\
10 \mathrm{kV} \text { overhead line from } \\
\text { the "Kilyanki" substation }\end{array}$ & $\begin{array}{l}\text { Churapcha } \\
\text { district, } \\
\text { Arylakh } \\
\text { village }\end{array}$ & $\begin{array}{l}19.02 . \mathrm{Feb} \\
\text { ruary } \\
2014,3: 34 \\
\text { am }\end{array}$ & $\begin{array}{l}19 \\
\text { February } \\
2014,2: 10 \\
\text { pm }\end{array}$ & Falling tree onto wires & - & - \\
\hline 2 & $\begin{array}{l}\text { Supply of heat transfer } \\
\text { agent was stopped in } 12 \\
\text { residential buildings }\end{array}$ & $\begin{array}{l}\text { Ust-Maisky } \\
\text { district, } \\
\text { Petropavlovsk } \\
\text { village }\end{array}$ & $\begin{array}{l}26 \\
\text { January } \\
2014,7: 00 \\
\text { pm }\end{array}$ & $\begin{array}{l}26 \\
\text { January } \\
2014, \\
10: 25 \text { am }\end{array}$ & $\begin{array}{l}\text { An unidentified track } \\
\text { brought down a section } \\
\text { of the heating main, } \\
\varnothing 100 \mathrm{~mm} \text { supply, and } \\
\text { return pipelines damage }\end{array}$ & - & - \\
\hline 3 & $\begin{array}{l}\text { Stop of the boiler house } \\
\text { "Kvartalnaya". Heat } \\
\text { supply for } 17 \text { private } \\
\text { residential buildings, } 1 \text { of } \\
16 \text { apartment buildings } \\
\text { and } 10 \text { socially objects } \\
\text { was disrupted (the houses } \\
\text { have stove heating) }\end{array}$ & $\begin{array}{l}\text { Vilyui district, } \\
\text { Khalbatsy } \\
\text { village }\end{array}$ & $\begin{array}{l}29 \\
\text { January } \\
2014,1: 55 \\
\text { pm }\end{array}$ & $\begin{array}{l}29 \\
\text { January } \\
2014, \\
7: 30 \mathrm{pm}\end{array}$ & $\begin{array}{l}\text { Ignition of sawdust on } \\
\text { the roof of the building }\end{array}$ & - & - \\
\hline 4 & $\begin{array}{l}\text { Fire in the boiler room } \\
\text { "Shkolnaya" ( } 4 \text { boilers, } \\
\text { fuel oil) }\end{array}$ & $\begin{array}{l}\text { Lensky } \\
\text { district, } \\
\text { Peleduy } \\
\text { settlement }\end{array}$ & $\begin{array}{lr}24 & \text { April } \\
2013,3: 45 \\
\text { pm }\end{array}$ & $\begin{array}{l}24 \text { April } \\
2013, \\
1: 10 \mathrm{pm}\end{array}$ & - & - & 540 \\
\hline
\end{tabular}


An analysis of measurements of the microhardness of welded joints made of 09G2S steel, used for metal structures in the North and the Arctic, was carried out, which showed that the ambient temperature practically does not affect the distribution of microhardness in the heat-affected zone (HAZ) of the welded joint, despite the significant difference in cooling rates. However, the accumulation of damage in the welding zone and HAZ is facilitated by the process of crack growth along grain boundaries, the intensity of which depends on the stiffness of the stress-strain state (SSS). High inhomogeneity of mechanical properties causes localization of stresses at microcracks and micropores. Thus, low values and high temperature gradients provoke the formation of cold cracks in the elements of welded [11] and cast structures, and also causes the destruction of elements of parts made of hardened steels [12].

On the basis of theoretical and experimental studies, a criterion for assessing the resource of structural elements is proposed, taking into account the phenomenon of ductile-brittle transition in steel by changing the value of the impact toughness $\mathrm{KCV}$. Assessment of damage to metal structures during operation in different climatic zones of Russia shows significant differences (see Fig.), Which explains the earlier depletion of the resource of engineering systems in regions with extreme natural conditions [13].

At low climatic temperatures, the process of accumulation of total damage is significantly affected by a decrease in the plasticity of the material, measured by the value of impact strength. In this case, the stress-strain state of the elements of metal structures becomes much more rigid due to low climatic operating temperatures, at which a ductile-brittle transition occurs in the steels with the bcc structure [14].

Thus, it has been shown that, under low climatic temperatures, the process of accumulation of total damage is significantly affected by a decrease in the plasticity of the material, measured by the value of impact strength. In this case, the stress-strain state of the elements of metal structures becomes much more rigid due to low climatic operating temperatures, when a ductile-brittle transition occurs in the steels with the bcc structure (see Fig. 1).

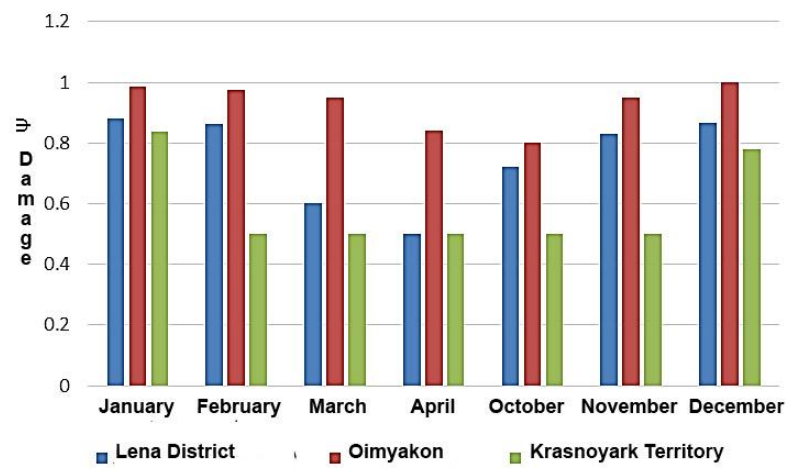

Fig. 1. Calculation of damage to metal structures made of steel 09G2S according to the data of average monthly temperatures for the regions of the North.

\section{New security concept: Industry $\mathbf{5 . 0}$}

A number of key probabilistic factors affecting safety and their interaction are not adequately taken into account, for example, the spread of properties and the accumulation of damage in the material, defectiveness of welds, external influences, as well as unskilled personnel actions, which leads to the inevitability of failures and disasters. not to prevent them. An expert, mostly economic, decision on the acceptability of risk makes it possible to avoid solving the complex problem of eliminating an accident or disaster, and leads to the inevitability of human casualties.

Until now, in modern regulatory documents, the probability of an accident or equipment failure is expressed as a classical probabilistic value, assessed by an acceptable, or admissible, statistical risk. The calculation of the probability is carried out without taking into account a priori knowledge, clarifying the values as a result of the history of observations and modeling. From the point of view of safety, setting the value of an acceptable risk allows us to get away from the general problem of protection against accidents and disasters, and reduce it to an economic problem [15].

A number of key probabilistic factors affecting safety and their interaction are not adequately taken into account, for example, the spread and change in material properties during operation, defectiveness and damage accumulation in welded structures, unskilled personnel actions (the so-called human factor), which leads to the inevitability of failures and disasters, and not to their prevention.

The application of approaches based on the nonMarkov paradigm, in particular, on the Bayesian interpretation of probability, to assess the safety and resource of technology, will make it possible to make clearer predictions and prevent casualties caused by man-made factors [16].

The complexity of describing non-Markov processes is their nonlocality in time, mathematically expressed in the form of integro-differential equations, which determine the evolution of the system. One of the consequences of taking into account the history of occurring events is a change in the probabilistic picture. From the classical frequency one is moving to the Bayesian interpretation of probability, when it can be defined not as an objective accident, but as a measure of ignorance, decreasing with the receipt of additional information about the event. From this point of view, the Bayesian approach is a generalization of Boolean logic, it is more grounded and mathematically correct.

The simplest case of a non-Markov process is considered - the accumulation of damage and the destruction of a railroad wheel rim. In order to estimate the wheel temperature during operation and the corresponding reduction in toughness, a Bayesian approach was applied to estimate the probability: 


$$
p(\theta \mid T)=\frac{p(T \mid \theta) p(\theta)}{\int_{\theta_{0}}^{\theta_{n}} p(T \mid \theta) p(\theta) d \theta}
$$

where $p(\Theta \mid T)$ is a priori knowledge of the value of $T$, and probability of observing of a sample temperature $T=\left(T_{1}, \ldots T_{n}\right)$ is determined by the value $\mathrm{p}(T \mid \Theta)$.

The general condition of destruction will look as follows [17]:

$$
\psi=\sum_{i=1}^{N} \frac{\Delta n}{N_{i}(T)}+\sum_{j=1}^{K} \frac{\Delta J_{j}}{J_{C}(T)}=1
$$

where $\psi$ is a damage of material, $n$ and $N$ - number of current and maximum cycles of loading, $J$ and $J_{C}$ are the $J$-integral of the plastic zone near crack.

Determining the value of the J-integral in the general case is a rather difficult task in the real operating conditions. Therefore, one cold be used the available calculated and empirical dependencies for other characteristics of the fracture process.

Known logistic dependence of the estimate of the total accumulation of damage at different structural levels of deformation, as well as the correlation between the impact toughness $K C V$ and fracture toughness $J_{I C}$ at equal test temperatures, allows us to estimate the second term in (2).

So, proceeding from the well-known relation for the $J$-integral, assuming equal velocities of the dynamic impact on the wheel from the rail at different sections of the track, it can be assumed $J_{I C}=K_{I C}{ }^{2} / 2 G$, where Gand $E$ is Young's modulus of elasticity, and $\mu$ is Poisson's ratio. Whence, taking into account the associated flow law:

$$
\psi_{T}=\frac{1}{K} \sum_{j=1}^{K}\left[\left(1-\frac{K C V_{j}}{K C V_{0}}\right)^{m}\right],
$$

where $K C V_{0}, K C V_{j}$ - impact toughness at room temperature, and at the moment of the $j$-th damage, respectively, $\mathrm{m} \sim 0.25-0.3$ is a coefficient depending on the material and type of stress-strain state.

Taking into account (1), (2) and (3), the condition for the destruction of the locomotive wheel in general form will look as follows:

$$
\psi_{T}=\frac{1}{K} \sum_{j=1}^{K}\left[\left(1-\frac{K C V_{j}}{K C V_{0}}\right)^{m}\right],
$$

A numerical calculation of the damage accumulated in the tire of the locomotive wheel, taking into account the effect of low temperatures on the decrease in plasticity, was carried out, according to (3) and (4). On the section of the Neryungri-Tommot railway, the damage measure was $\Psi_{L}=0.851$, while in the Moscow region, the calculation of the relative damage according to (1) gives the value $\Psi_{L}=0.364$, which is more than 2-3 times lower than for the Neryungri-Tommot section in
Yakutia. In reality, however, damage due to more severe operating conditions (the gap between the rails and the shock load will be much higher at low temperatures) differ even more. The experience of operating locomotives on the railway in the conditions of Sakha Republic (Yakutia) shows a threefold reduction in the service life of wheels compared to the resource in regions with a temperate climate.

Extreme natural conditions inherent in the regions of the Far North, Arctic and Subarctic, exacerbate a number of problems associated with the technical condition of objects in a very cold climate, and exacerbate, as the analysis shows [18], the impact of the human factor. Therefore, the new concept of ensuring security in the context of digital transformation should provide for the functioning of appropriate monitoring and control systems that take into account the impact of the environment on the technical condition of facilities and operators who ensure their operation. In the context of a recurring pandemic of viral diseases, the health indicators of workers can also be monitored along the way. The digitalization of energetics and engineering science leads to realization of Programs Industry 4.0 [1920]:

- interoperability (compatibility of internet connections of humans, cyber-physical systems and "smart factories");

- virtualization (creation of virtual model);

- decentralization (by making use of Artificial Intelligence 'AI', Internet of Things 'IoT', Industrial Internet 'II', Cloud Computing ' $\mathrm{CC}$ ');

- real-time operation for monitoring and evaluation of complex engineering systems operation and human security.

On Fig. 2 shown the possible combining IoT, Industry 4.0 Programme, and energy management that suggest exciting future in Society 5.0.

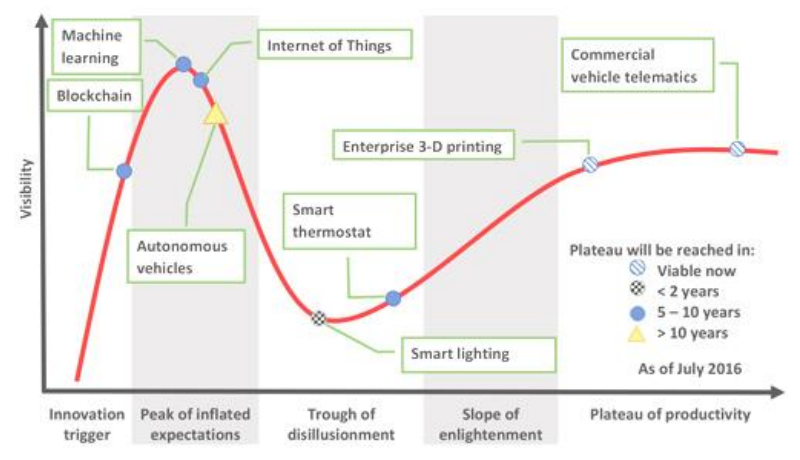

Fig. 2. Hype cycle of selected Internet of Things technologies (adapted from Gartner).

But the new concept should be more close to nature and shapes the Industry 5.0 main features:

- environment-friendly technologies, regeneration of natural resources;

- machine-learning Artificial Intelligence, Neural Networks and Neural Interfaces;

- abilities of self-heal damages and repair defects; 
- Quantum Algorithms, Quantum Security and Quantum Encryption;

- self-assembly and self-improving by human supervision;

- Human Security as priority principle.

\section{Conclusion}

The new security concept for transport and energy complex engineering systems operated in cold climate should include the information from the monitoring and flexible control systems that takes into account the states of extreme environment, the engineering system damage and the operator health. The 'absolute safety' concept could be seen as a guarantee of minimal protective measures [21]. The damage accumulation processes in the complex engineering systems should by control by machine-learning artificial intelligence and switch the operation to repair and reconstruction stages.

It is proposed to move from consumer society technologies, defined by the concept of "acceptable risk" and "sustainable development" to a new concept of security based on renewable development, environmentfriendly technologies for the extraction and processing of natural resources, closed production, using the achievements of the modern information society and Industry 4.0, which allows laying the foundations for the implementation of the upcoming Industry 5.0. This will mitigate the consequences of the global economic and social crisis and avoid scenarios of archaic or postapocalyptic worlds.

This work has been supported by the Russian Foundation for Basic Research (Project 18-48-140015) for numerical calculations and by the Program for Basic Research of State Academies of Science (Project III.28.1.1.) for experimental part with the using of equipment of the Center for Collective Use of Federal Research Center "Yakut Scientific Center".

\section{References}

1. V.R. Amirov, Management of Reliability and Integrity of Equipment is an Important Tool for Enhancing Business Efficiency, PROneft. Prof. about Oil E 1(7), pp. 77-80 (2018)

2. S.N. Gusarova, Yu.M. Erokhina, O.V. Kuzmicheva, Using of Risk-Oriented Thinking in Testing Laboratories, Ind. Lab. Diag. of Mat. E 85(8), pp. 70-78 (2019)

3. M. Castells, The Information Age: Economy, Society and Culture. Vol. I-II (2000)

4. I.I. Kuzmin, D.A. Shaposhnikov, Safety Concept: from "Zero" Risk to "Acceptable", Herald of the RAS E 64(5), pp. 402-408 (1994)

5. M.M. Legasova, The Way to Safety Concept, J. of the Mendeleev All-Union Chem. Soc. E 35(4), pp. 405-408 (1990)
6. V.A. Akimov, V.V. Lesnykh, N.N. Radaev, Fundamentals of Risk Analysis and Management in the Natural and Technogenic Spheres (2004)

7. Security of Russia. Legal, Socio-Economic and Scientific and Technical Aspects. Glossary of Terms and Definitions (1999)

8. V.V. Velichenko, To Disaster Management Problem, Proc. of the Acad. of Sci. E 349(6), pp. 732-735 (1996)

9. O.I. Sleptcov, A.I. Levin, G.P. Struchkova et al., Safety of the Republic of Sakha (Yakutia): Social, Economic and Technogenic Problems (2008)

10. D.V. Prokhorov, Increasing the Reliability of Decentralized Energy Systems of Northern Territories (2018)

11. M.S. Bisong, V.E. Mikhailov, V.V. Lepov et al. Influence of the Thermal Cycle of Welding on Crack Resistance, Structure and Properties of LowAlloy Steels, Arct. and Subarct. Nat. Res. E 1, pp. 54-59 (2018)

12. V.V. Lepov, A.V. Grigoriev, A.M. Ivanov et al, Mechanisms of Damage to Materials and Elements of Steel Structures Operating in Extreme Conditions of the North, Arct. and Subarct. Nat. Res. E 2, pp. 67-75 (2018)

13. A.V. Grigoriev, V.V. Lepov, Estimation of the Reliability of 09G2S Steel Structures Operating in Arctic Conditions, Ind. Lab. Diagn. of Mat. E 85 (8), pp. 53-58 (2019)

14. A.V. Grigoriev, V.V. Lepov, Reliability and Resource of Engineering Systems in Extreme Operating Conditions of the Arctic and Subarctic: Railway Transport (2018)

15. V.V. Lepov, The Art of Decision-Making: Short History and State-of-the-Art, Educ. and Sci. E 2, pp. 93-97 (1996)

16. V.S. Achikasova, K.Ya. Lepova, V.V. Lepov, Fundamentals of Viscous-Brittle Transition and Fracture Modelling, In Collect.: Cold Resist. New Techn. for Equip. and Struct. of the North and the Arctic, pp. 67-72 (2016)

17. V.V. Lepov, Reliability and Resource of Technical Systems in Extreme Operating Conditions, Zavod. Lab. Diagn. of mat. E 86(6), pp. 36-39 (2020)

18. V.T. Alymov, N.P. Tarasova, Technogenic Risk. Analysis and Evaluation: a Textbook for Universities (2004)

19. D. Bell, The Coming of Post-Industrial Society: a Venture in Social Forecasting (1973)

20. M. Kuznetsova, Risks of the Industry 4.0 and their Influence on Industrial Organizations, Vestnik Universiteta E 11, pp. 115-122 (2018)

21. B.G. Volik, On the Concepts of Technogenic Safety, Autom. and Rem. Contr. E 2, pp. 165-170 (1998) 